\title{
Mediação Pedagógica: um estudo a partir da percepção de professores em formação continuada
}

\author{
Gianna Oliveira Bogossian Roque ${ }^{1}$, Stella Maria Peixoto de Azevedo Pedrosa ${ }^{1}$ \\ Gilda Helena Bernardino de Campos ${ }^{1}$, \\ ${ }^{1}$ Coordenação Central de Educação a distância \\ Pontifícia Universidade Católica do Rio de Janeiro - PUC-Rio \\ \{gianna, Stella,gilda\}@ccead.puc-rio.br
}

\begin{abstract}
Resumo: Este artigo apresenta um estudo inicial dos resultados de uma pesquisa quali-quantitativa que busca evidências da influência da ação da mediação pedagógica no desempenho acadêmico dos alunos. Para a sistematização das respostas foi utilizado o ALCESTE, software de análise de conteúdo. $O$ artigo destaca a relevância da mediação no desempenho profissional do aluno e sua importância na redução da evasão.
\end{abstract}

Palavras-chave: mediação pedagógica, educação a distância, análise de conteúdo

\begin{abstract}
This paper presents a study of initial results of qualitative and quantitative evidence that seeks to influence the action of mediation in students' academic performance. For systematization of answers, it has been used the ALCESTE, a content analysis software. The article highlights the importance of mediation in student's professional performance and its importance in reducing course evasion.
\end{abstract}

Key words: pedagogical mediation, distance education, content analysis

\section{Introdução}

Os cursos a distância caracterizam-se pela existência de uma distância temporal e espacial entre professor e aluno. Essa é vencida pela interação que ocorre entre esses atores por meio da utilização das tecnologias de informação e comunicação, interação essa essencial para que a mediação didático-pedagógica ocorra de fato.

Nesse contexto, a mediação pedagógica tem sido foco de vários debates no âmbito da Educação a Distância e diferentes autores têm demonstrado seu entendimento sobre esse conceito, enfatizando a ação e a importância do mediador no processo ensino aprendizagem (MASETTO, 2000; BELLONI, 2001; CAMPOS, ROQUE e AMARAL, 2007).

Esse artigo descreve parte dos resultados de uma pesquisa quali-quantitativa com alunos, professores em formação, de um curso de especialização em Tecnologias em Educação, oferecido por meio de uma parceria do governo federal com uma instituição de Ensino Superior, realizado no período de agosto/2009 a dezembro/2010. A questão analisada nesse artigo buscou verificar a percepção dos próprios cursistas sobre a ação dos mediadores pedagógicos. A interação entre esses atores ao longo do 
curso foi realizada por meio dos mecanismos de comunicação disponibilizados no Ambiente Virtual de Aprendizagem e-ProInfo.

\section{Descrição do estudo}

O referido curso ofereceu 6.030 vagas das quais 5.852 foram preenchidas por professores e profissionais da educação distribuídos por todas as Unidades da Federação. A fim de acompanhar os cursistas, distribuídos em 208 turmas, foi formada uma equipe com 110 mediadores pedagógicos, cada um responsável por uma ou duas turmas, de até 30 alunos. Vale destacar que esse curso foi realizado totalmente a distância, ou seja, sem momentos de estudo presencial, tendo o mediador pedagógico como atribuições a dinamização do espaço de aprendizagem, o atendimento individualizado dos alunos, as orientações relativas aos conteúdos abordados nas disciplinas por meio do estabelecimento do diálogo dos alunos com os materiais de estudo e a avaliação da aprendizagem. Entendemos que a qualidade da interação estabelecida entre mediador-aluno é fundamental para a qualidade da mediação pedagógica propriamente dita.

O objetivo central da pesquisa realizada foi averiguar como os alunos significavam o que é qualidade em cursos a distância. Para tal, tomou-se como base um questionário composto por 25 questões objetivas e 4 questões discursivas disponibilizado de forma on-line, resguardando a identidade dos respondentes. Tal instrumento foi encaminhado ao final do curso a todos os alunos concluintes, obtendose 2.090 respostas, o que corresponde a $61,8 \%$ dos que estavam regularmente matriculados na ocasião da pesquisa, distribuídos conforme os gráficos abaixo.
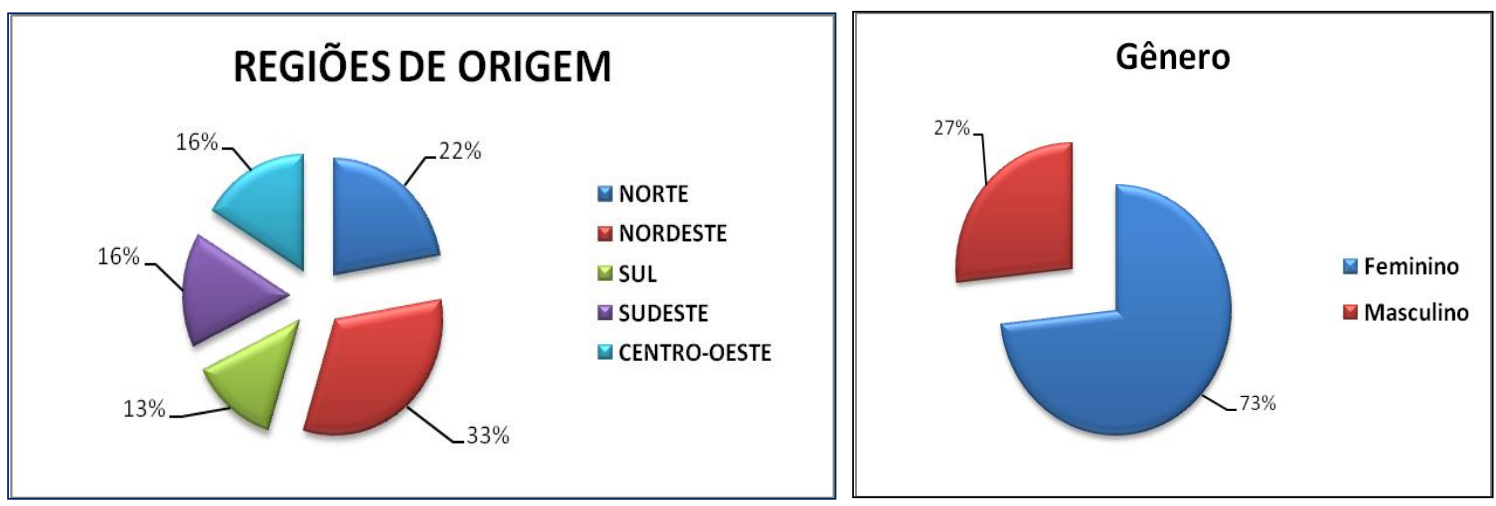

Grafico 1- Perfil dos respondentes

As 25 questões objetivas foram agrupadas nos diferentes constructos que buscavam evidencias da qualidade do curso, ou seja: conteúdo/material didático; tarefas e avaliação; ferramentas de comunicação (fóruns e diário de bordo); mediadores pedagógicos; ambiente de aprendizagem; suporte técnico; além de uma autoavaliação.

As questões abertas, por sua vez, solicitavam a opinião dos alunos sobre a mediação pedagógica, a orientação do trabalho de conclusão, a importância do curso para sua vida profissional, além de sugestões de mudanças no curso. A questão analisada nesse artigo buscou verificar a forma na qual o mediador pedagógico 
contribuiu para o desempenho acadêmico do aluno. Seu objetivo foi verificar como os alunos, professores da rede pública de ensino, avaliaram a ação do mediador.

A análise da questão em referência foi realizada por meio da análise de conteúdo, que compreende a análise interpretativa dos registros textuais de todos os respondentes da pesquisa. Para Kronberger e Wagner (2007), tal análise pode ser realizada tanto manualmente - a partir da leitura, categorização e agregação dos conceitos presentes na fala dos respondentes - quanto por meio de procedimentos estatísticos automáticos que fazem uso de programas informatizados.

Nessa pesquisa foi utilizado o Programa ALCESTE - Analyse Lexicale par Contexte d'un Ensemblement de Segment de Texte ${ }^{1}$, criado por Max Reinert, o que contribuiu especialmente, pois, o material textual (corpus de análise) era volumoso devido ao grande número de respondentes, tornando a análise manual extremamente complexa.

Para o processamento e análise das respostas, o ALCESTE verifica a coocorrência de palavras nos enunciados que constituem o corpus da pesquisa e apresenta como resultado as informações consideradas relevantes para uma análise de conteúdo. $\mathrm{O}$ objetivo do ALCESTE é investigar as semelhanças e dessemelhanças estatísticas das palavras, denominadas pelo software como "formas reduzidas", com o objetivo de identificar e "distinguir classes de palavras que representem diferentes formas de discurso a respeito do tópico de interesse" (KRONBERGER e WAGNER, 2007, p.427).

Os resultados do ALCESTE permitiram que as respostas fossem distribuídas em quatro classes. Essa organização inicial contribuiu para que os dados coletados fossem organizados para uma posterior análise de conteúdo (BARDIN, 1979), ou seja, um estudo minucioso, no qual se procura desvendar o que está por trás das palavras recorrentes.

\section{Análise dos dados}

O corpus de análise foi composto por todas as respostas obtidas referentes à questão estudada. Cada uma delas constitui uma unidade de contexto inicial (UCI) que, para a consecução da análise são ainda decompostas pelo programa em UCE (Unidade de Contexto Elementar).

O dendograma obtido pelo programa (Figura 1) apresenta o agrupamento das formas reduzidas identificadas na análise, por classe. Cada uma delas foi observada dentro do contexto, ou seja, nos depoimentos dos alunos. A partir dessa análise tornouse possível interpretá-las e nomeá-las.

\footnotetext{
${ }^{1}$ Análise Lexical por Contexto de um Conjunto de Segmentos de Texto.
} 


\begin{tabular}{|c|c|c|c|c|c|c|c|}
\hline \multicolumn{2}{|c|}{ CLASSE 1} & \multicolumn{2}{|l|}{ CLASSE 2} & \multicolumn{2}{|c|}{ CLASSE 3} & \multicolumn{2}{|c|}{ CLASSE 4} \\
\hline \multicolumn{2}{|c|}{$\begin{array}{c}\text { Melhora do } \\
\text { desempenho } \\
\text { profissional do } \\
\text { aluno } \\
\end{array}$} & \multicolumn{2}{|c|}{$\begin{array}{c}\text { Apoio em relação às } \\
\text { dúvidas }\end{array}$} & \multicolumn{2}{|c|}{$\begin{array}{c}\text { Intervenção na } \\
\text { realização das } \\
\text { atividades e nos fóruns }\end{array}$} & \multicolumn{2}{|c|}{$\begin{array}{l}\text { Permanência e } \\
\text { sucesso no curso }\end{array}$} \\
\hline \multicolumn{2}{|c|}{459 u.c.e. $-21,0 \%$} & \multicolumn{2}{|c|}{408 u.c.e. $-19,0 \%$} & \multicolumn{2}{|c|}{282 u.c.e. $-13,0 \%$} & \multicolumn{2}{|c|}{1011 u.c.e. $-47,0 \%$} \\
\hline FORMES & KHI2 & FORMES & KHI2 & FORMES & KHI2 & FORMES & KHI2 \\
\hline conheci & 235 & duvida & 690 & forun & 291 & curs & 204 \\
\hline tecnolog & 229 & $\operatorname{san}$ & 202 & dos & 220 & mediador & 197 \\
\hline pratic & 200 & tir & 195 & comentar & 142 & foi & 145 \\
\hline aula & 167 & as & 100 & das & 140 & conclu & 60 \\
\hline sala & 151 & solicit & 65 & atraves & 129 & nao & 60 \\
\hline educac & 149 & orient & 63 & atividade & 122 & do & 57 \\
\hline escol & 131 & sempre-que & 62 & particip & 114 & ela & 46 \\
\hline uso & 119 & dando & 61 & discuss & 106 & muito & 38 \\
\hline utiliz & 106 & minhas & 60 & compreen & 91 & fundament & 37 \\
\hline mid & 98 & esclareci & 54 & prazo & 79 & um & 36 \\
\hline ensin & 74 & necessar & 52 & questionamento & 56 & desist & 32 \\
\hline recurso & 73 & sugest & 40 & etc & 54 & pessoa & 30 \\
\hline nov & 68 & atendendo & 39 & contribuicoes & 48 & uma & 29 \\
\hline busc & 64 & surg & 39 & cumprimento & 48 & final & 28 \\
\hline novos & 60 & sanadas & 37 & via & 48 & cheg & 27 \\
\hline TICs & 56 & dificuldade & 36 & lembretes & 47 & turma & 27 \\
\hline profissional & 54 & precis & 35 & provoc & 46 & not & 26 \\
\hline ampli & 52 & esclarecendo & 34 & postadas & 39 & parabens & 25 \\
\hline aprendiz & 51 & surgidas & 34 & forum & 37 & falt & 24 \\
\hline teor & 51 & todas & 34 & execuc & 33 & mar & 24 \\
\hline na & 50 & esclarec & 32 & email & 32 & apoi & 23 \\
\hline construc & 44 & habil & 28 & orientacoes & 32 & competent & 22 \\
\hline de & 40 & prontamente & 27 & nas & 30 & importancia & 22 \\
\hline form & 40 & auxili & 26 & nos & 30 & medi & 21 \\
\hline aprend & 39 & pront & 25 & elabor & 27 & otim & 21 \\
\hline ferramenta & 38 & possive & 24 & direcionamento & 26 & longo & 20 \\
\hline proporcion & 38 & quando & 22 & incentiv & 26 & seu & 20 \\
\hline reflet & 38 & todas-as-vezes-que & 22 & mail & 26 & inici & 19 \\
\hline aplic & 36 & suporte & 21 & solicitadas & 26 & presenca & 19 \\
\hline lev & 35 & hora & 19 & tem & 26 & que & 19 \\
\hline enriquec & 33 & caminhos & 18 & debat & 25 & compreensiva & 18 \\
\hline inovador & 33 & necessit & 17 & grupo & 24 & essenci & 18 \\
\hline contexto & 32 & resolv & 17 & instig & 24 & sent & 18 \\
\hline las & 32 & soluc & 17 & realizadas & 24 & todos & 18 \\
\hline meus & 32 & surgindo & 17 & envi & 23 & carinh & 17 \\
\hline TIC & 31 & apresent & 15 & alert & 22 & continuidade & 16 \\
\hline inserc & 30 & atividade & 15 & aprofundamento & 21 & da & 16 \\
\hline educacion & 28 & atendid & 14 & individu & 21 & teve & 16 \\
\hline possibilidade & 28 & eficaz & 14 & post & 21 & dedic & 15 \\
\hline
\end{tabular}

Figura 1 - Dendograma - Fonte: Dados analisados

A Classe 1 foi composta pelas palavras reduzidas que, analisadas no contexto das respostas dos alunos, evidenciaram que seu desenvolvimento profissional foi aprimorado no curso. Nessa perspectiva a mediação pedagógica forneceu elementos que contribuem para o conhecimento e a prática desses alunos no seu cotidiano como profissionais da educação, o que corrobora com o conceito de mediação apresentado por Masetto:

(...) a atitude, o comportamento, do professor que se coloca como facilitador, incentivador ou motivador da aprendizagem, que se apresenta com a disposição de ser uma ponte entre o aprendiz e sua aprendizagem, não uma ponte estática, mas uma ponte 'rolante', que ativamente colabora para que o aprendiz chegue aos seus objetivos. É a forma de apresentar e tratar um conteúdo ou tema que ajuda o aprendiz a coletar informações, relacioná-las, organizá-las, manipulá-las, discutilas e debatê-las com seus colegas, com o professor e com outras pessoas 
(interaprendizagem), até chegar a produzir um conhecimento que seja significativo para ele, conhecimento que se incorpore ao seu mundo intelectual e vivencial, e que o ajude a compreender sua realidade humana e social, e mesmo a interferir nela. (MASETTO, 2000, p.144)

No caso da EAD essa "figura do professor" é distribuída entre os muitos profissionais que participam do processo, desde os que elaboram o conteúdo aos que tem contato mais direto com os alunos, passando pelos responsáveis pela apresentação do conteúdo, pela equipe administrativa, entre outros que muitas vezes o aluno sequer tem conhecimento de sua existência.

As formas reduzidas que se sobressaíram na Classe 1 foram: conheci+, tecnolog + , pratic + , aula, sala, educac + , escol $+^{2}$. Essas formas nortearam o agrupamento dos depoimentos pertencentes a essa Classe, nomeada como "Melhora do desempenho profissional do aluno", e que sinalizaram a forma na qual os conhecimentos sobre o uso das tecnologias em sala de aula foram aprimorados no curso. Como exemplo de depoimentos pertencentes a essa classe, temos:

Acredito que as atividades propostas foram bem elaboradas, pois, permitiam ampliar as reflexões teóricas dos temas abordados como também impulsionaram a desenvolver atividades praticas com o uso das tecnologias na educação. $\left(* I n d \_1143 *\right.$ Gen_F $*$ Turma_PR04 *Rede_E)

(...) foram muito importante para que se refletisse sobre a pratica docente alem-de poder avaliar tanto o trabalho da escola como do professor no tocante a insercao das TIcs no espaco escolar como forma de dinamizar o processo de ensino aprendizagem (*Ind_1698 *Gen_M *Turma_PE02 *Rede_E).

Cabe ressaltar que o objetivo principal do curso, além de ampliar o conceito de educação mediada e integrada por tecnologias com a incorporação de todos os meios tecnológicos cabíveis, era propiciar aos professores a utilização dessas tecnologias no contexto de sala de aula. As respostas agrupadas na Classe 1 evidenciam o cumprimento desse objetivo.

Huberman (1999) ressalta que até o século XIX, o papel do professor era o de condutor do processo de ensino, cabendo-lhe toda a responsabilidade da aprendizagem e que posteriormente esse papel modificou-se e ele passou a ser o de facilitador do processo ensino-aprendizagem. Nas Classes 2 e 3 encontramos pontos relacionados às práticas fim do mediador, ou seja, sua função de dinamizador das discussões no fórum, avaliação da aprendizagem, correção e feedback das atividades realizadas, ponte entre os alunos e os conteúdos das disciplinas, entre outras.

A Classe 2 agrupa as respostas que enfatizam o apoio dos mediadores sempre que surgiam dúvidas. Não podemos ignorar que na mediação pedagógica, o diálogo necessita ser constante, pois é fundamental "codificar as mensagens pedagógicas, traduzindo-as sob diversas formas" (BELLONI, 2001, p.63). Nesta Classe 2 as palavras com o maior valor de qui-quadrado, ou seja aquelas que sinalizaram o sentido da classe foram: dúvida, san+, tir + , solicit+, orient+.

\footnotetext{
${ }^{2} \mathrm{O}$ sinal de "+" ao lado de algumas formas reduzidas indica que há uma associação de palavras, ou seja, educac+ indica o conjunto de palavras: educação, educar, educacional etc., encontradas no corpus da pesquisa.
} 
A mediação pedagógica se fez presente durante todo o curso atendendo as minhas solicitações, tirando dúvidas, indicando caminhos e principalmente estimulando a aprendizagem. $\left(* I n d \_188 * G e n \_M * T u r m a \_B A 07 * R e d e \_E\right.$ )

O mediador sempre que necessitei esteve pronto a ajudar me em tempo habil, tirando dúvidas, acrescentando sugestões, fazendo com que minhas atividades fossem realizadas de maneira correta e com o entendimento correto do que era solicitado (*Ind_316*Gen_F*Turma_ESO2 *Rede_M)

Por sua vez, a Classe 3, interpretada como "Intervenção na realização das atividades e nos fóruns" reúne pontos relacionados à ação do mediador, tanto na elaboração e correção das tarefas propostas, como na interação nos fóruns de debates.

Vale destacar que, para Lévy, em um sistema de educação a distância

O essencial se encontra em um novo estilo de pedagogia, que favorece ao mesmo tempo as aprendizagens personalizadas e a aprendizagem coletiva em rede. Nesse contexto, o professor é incentivado a tornar-se um animador da inteligência coletiva de seus grupos de alunos em vez de um fornecedor direto de conhecimentos (Lévy, 1999, p. 158).

Entretanto, deve-se ter claro de que docente não é o único responsável pelo processo ensino aprendizagem, pois:

a mediação pedagógica coloca em evidência o papel do sujeito do aprendiz e o fortalece como ator de atividades que lhe permitirão aprender e conseguir atingir seus objetivos; e dá um novo colorido ao papel do professor e aos novos materiais e elementos com que ele deverá trabalhar para crescer e se desenvolver (MASETTO, 2000, p.146).

As respostas contidas na Classe 3 confirmam as afirmativas de Masseto sobre o diálogo estabelecido pelo mediador, ao "apresentar perguntas orientadoras; orientar nas carências e dificuldades técnicas ou de conhecimento quando o aprendiz não consegue encaminhá-las sozinho; desencadear e incentivar reflexões" (2000, p.145).

Assim, vale observar que as palavras reduzidas que se sobressaíram na Classe 3 foram: fórum + , comentar + , através, atividade, particip + , discuss + , compreen + . Os depoimentos abaixo, agrupados nessa classe ilustram a opinião dos alunos sobre a forma na qual a mediação pedagógica contribuiu para o seu desempenho acadêmico.

(...) norteando as discussões do fórum para a temática estudada; excelente mediação dos conflitos na execução dos trabalhos em grupo, seminários, $e$, sobretudo, concluindo as discussões dos fóruns com inferências significativas que trouxeram-me aprendizado. (*Ind_1481 *Gen_F *Turma_SP08 *Rede_E)

(...) essencial durante todo o curso, para a melhor compreensão das atividades solicitadas, cumprimento dos prazos de entrega, fortalecer nossa participação e continuidade no curso e principalmente para a qualidade na elaboração das atividades individuais e coletivas (*Ind_1280 *Gen_F *Turma_SC05 *Rede_M). 
Tanto a Classe 2 quanto a Classe 3 confirmam o alcance de uma das diretrizes para os mediadores do curso: a postura participativa, evidenciando que "a mediação tem como uma de suas bases a comunicação, porém o que vai caracterizá-la é o caráter das interações construídas" (SOUZA, SARTORI e ROESLER, 2008, p.333).

Ao mediador toca promover uma série de atividades junto aos alunos, precisando estar atento para a individualização de suas intervenções, de modo a incentivar o desenvolvimento tanto do potencial cognitivo quanto do emocional de cada aluno (SMERIGLIO, 2008).

Segundo Diaz (2002 apud PALLOFF e PRATT, 2004), algumas razões podem interferir no andamento de um curso on-line, gerando a evasão de alunos, como, por exemplo: fatores educacionais, no que se referem à qualidade do material didático; dificuldade de compreensão do material; e, sobretudo, apoio oferecido pelo professor e pela instituição.

Nesse contexto, percebe-se que a Classe 4 sinaliza, justamente, para a importância do mediador pedagógico no sucesso do curso e, mais enfaticamente, como fundamental para a permanência e conclusão do mesmo. As palavras reduzidas que se destacaram nessa classe são: curs + , mediador, conclu+, muito, fundament + , desist + .

(...) caso não haja uma boa comunicação do cursista com o mediador, ele termina abandonando. Por isso penso que a mediação no meu caso, foi fundamental, não só para o desempenho no curso, mas para a conclusão mesmo $\left(* I n d \_179 * G e n \_M * T u r m a \_P E 06 * R e d e \_M\right)$.

A persistência da mediadora em fazer com que acompanhássemos o desenvolvimento do curso foi extremamente importante para que continuasse atuando e desenvolvendo as atividades. (*Ind_508*Gen_M *Turma_SE07 *Rede_E)

(...) acredito que só consegui chegar ao termino do curso devido a colaboração ativa da nossa mediadora, pois ela foi incansável. (*Ind_1618 *Gen_F*Turma_PIO5*Rede_E)

Embora iniciais, os estudos sobre cada uma das classes identificadas nos depoimentos dos alunos e agrupadas pelo ALCESTE contribuíram para uma reflexão teórica sobre a prática do mediador pedagógico. Fornecem, ainda, subsídios para o aprofundamento da análise de conteúdo e de estudos específicos das diferentes questões apresentadas pelos alunos.

\section{Considerações Finais}

A ação da mediação pedagógica foi percebida pelos alunos no apoio recebido durante a realização das atividades e na interação nos fóruns propostos. É interessante observar que nas respostas não apareceu qualquer referência à necessidade da presença física do mediador. Portanto, ao que parece o que é esperado dos mediadores pedagógicos é que 
eles apoiem os alunos, mediando ou intermediando a realização de variadas atividades e o uso das ferramentas disponibilizadas no ambiente de aprendizagem.

Nesse locus, percebe-se que em todo o processo de desenvolvimento do curso a tutoria ou a mediação pedagógica aparece como uma atividade permanente e individualizada que tem por objetivo o acompanhamento dos alunos e o oferecimento a cada um do auxílio necessário ao processo de autoaprendizagem.

Esses dados podem ser um indicador de que com o amadurecimento da EAD abrem-se novas perspectivas para o trabalho docente, desde que resguardem-se a comunicação direta e o atendimento individual do aluno.

Apesar da questão central da pesquisa ter sido voltada para a busca de evidências da contribuição da mediação pedagógica no desempenho acadêmico dos cursistas pelo olhar dos próprios alunos, suas ações foram reconhecidas, também, como importantes para a melhora do seu desempenho profissional, objetivo principal do curso, além de ter sido apontada como causa da própria permanência do aluno no curso.

\section{Referências Bibliográficas}

BARDIN, L. Análise de Conteúdo. Lisboa: Edições 70, 1979.

BELLONI, M. L.O que é mídia-educação. São Paulo: Autores Associados, 2001.

CAMPOS, G.H.B, ROQUE, G.O.B, AMARAL, S.B., Dialética da Educação a Distância, Rio de Janeiro, Editora PUC Rio, 2007.

HUBERMAN, S. Cómo se forman los capacitadores: arte y saberes de su profesión. Buenos Aires: Paidós, 1999.

KRONBERGER, N., WAGNER, W., Palavras-chave em Contexto: análise estatística de textos, IN. BAUER, Martin W.; GASKELL, George. Pesquisa qualitativa com texto, imagem e som: Um manual prático. 6.ed. Petrópolis, Vozes, 2007, p.416441.

LÉVY, P. Cibercultura. São Paulo, SP: Ed. 34, 1999.

MASETTO, M.T. Mediação Pedagógica e o Uso da Tecnologia. In MORAN, J. M. MASETTO, M.T. e BEHRENS M. A. Novas Tecnologias e Mediação Pedagógica. Campinas: Papirus, 2000, p.133-173.

SMERIGLIO, D. Linee guida all' e-learning: Le nuove forme della didattica. Roma: Anicia, 2008.

SOUZA, A.R.B.; SARTORI, A. S.; ROESLER, J. Mediação Pedagógica na Educação a Distância: entre enunciados teóricos e práticas construídas. Revista Diálogo Educacional, v.8, n.24, p.327-339. Curitiba, maio/ago. 2008. 